\title{
Generosity Across Contexts
}

\author{
By Alexander L. Davis, John H. Miller, Roberto A. Weber*
}

Extensive research in economics explores generosity in monetary allocations, while generosity in non-laboratory contexts often involves the allocation of consumption goods or non-monetary harm. Psychological evidence suggests that generosity may be higher in such contexts. We compare generosity in decisions that vary whether allocations are monetary or non-monetary, and whether they involve utility gains or losses. In two experiments, generosity is higher in nonmonetary contexts. Thus, the typical monetary laboratory Dictator game may underestimate generosity in many non-laboratory contexts. We find a weak relationship between individuals' allocation decisions in monetary and nonmonetary contexts, but a strong relationship within monetary contexts.

\section{JEL Codes: D03, D64, C91}

Keywords: Altruism, generosity, harm, experiment

\footnotetext{
* Corresponding author: Alexander L. Davis; Department of Social and Decision Sciences, Carnegie Mellon University, Pittsburgh PA 15213, USA (e-mail: alexander.l.davis1@gmail.com); Materials and data can be obtained from the first author's Dataverse at http://dvn.iq.harvard.edu/dvn/dv/alexdavis. John H. Miller; Department of Social and Decision Sciences, Carnegie Mellon University, Pittsburgh, PA 15213, and the Santa Fe Institute, 1399 Hyde Park Road, Santa Fe, NM 87501 (e-mail: miller@ santafe.edu). Roberto A. Weber; Department of Economics, University of Zurich, Blümlisalpstrasse 10, 8006 Zurich, Switzerland (e-mail: roberto.weber@econ.uzh.ch). We gratefully acknowledge support from the research priority program at the University of Zurich "Foundations of Human Social Behavior." Research support from Carnegie Mellon University and the Santa Fe Institute is gratefully acknowledged.
} 


\section{Introduction}

Considerable research in economics seeks to understand when and why individuals engage in costly, other-regarding behavior (see, for example, Andreoni and Miller, 2002; Benabou and Tirole, 2006; and Fehr and Schmidt, 2006). The majority of this research examines the extent to which people are willing to share money with others, often using the Dictator game (Forsythe, et al., 1994; Frey and Bohnet, 1995; Andreoni and Vesterlund, 2001) and behavior in natural settings such as charitable donations (Falk, 2007; Karlan and List, 2007). The focus on sharing money is understandable, as monetary donations constitute a large and measurable example of other-regarding behavior. ${ }^{1}$

While the sharing of monetary wealth constitutes an appropriate focus for economic research on generosity, it is surprising that alternative forms of otherregarding behavior have been relatively neglected. One regularly observes costly generous behavior in non-monetary contexts. For example, individuals often incur or risk harm in order to lessen the harm to others. Consider two extremes examples: Moira Smith, a New York City policewoman, lost her life after running back into the Twin Towers to help others escape and Paul Rusesabagina risked his life to help Tutsis and Hutus escape the Rwandan genocide by letting them stay in his hotel (Dovidio, et al., 2006). Such extreme generosity appears, in fact, common to many life-and-death situations ${ }^{2}$ (Frey, Savage, and Torgler, 2011; Fischhoff, 2005). More routinely, members of the armed and emergency services often face large risks of life and limb to help others. People also often endure the certain harm of blood, organ, and bone marrow donations in order to reduce the harm to others-in the United States alone, about 6,000 organ donations per year come from living donors (OrganDonor.gov, 2010). There are also more routine

\footnotetext{
${ }^{1}$ Among the $70 \%$ of American households who give to charity, the average amount donated as a percentage of household income was 2.6\% in 2005 (Center on Philanthropy, Indiana University, 2008).

${ }^{2}$ Fischhoff, B. (2005). "A hero in every Aisle Seat.” New York Times, Op-Ed. August 7.

http://www.nytimes.com/2005/08/07/opinion/07fischhoff.html
} 
examples of generosity in the allocation of unpleasant experiences. For example, in firms, employees often choose to spend considerable time helping others with their work. Given the frequency and consequences of decisions involving nonmonetary generosity, both heroic and mundane, it is surprising that otherregarding behavior in these domains has not been more widely investigated by economists.

Here, we study other-regarding behavior across choice contexts. To better understand how generosity varies across contexts, we vary whether allocations involve positive or negative changes in utility and whether they are monetary or non-monetary. We also consider the extent to which an individual's generosity in one context is related to that same individual's generosity in other contexts.

We begin, in Experiment 1, by comparing the standard (monetary) Dictator game to a situation where the decision maker may choose to incur a nonpecuniary harm in order to mitigate a similar harm to another person. We choose this comparison for our initial study based on the apparently stark differences in generosity often observed between economic (dictator) and psychological (nonmonetary harm) experiments. As with the valuable early research that advanced our understanding of generosity in Dictator games, we begin our inquiry by using laboratory experiments in which we can exert control over the choice context.

In a second experiment, we extend our study to consider generosity in allocations over both monetary and non-monetary gains and losses. More precisely, we observe allocation choices in contexts that are monetary and positive, monetary and negative, nonmonetary and positive and nonmonetary and negative. This second experiment allows us both to replicate our findings from Experiment 1, using an alternative harmful experience, and to simultaneously more thoroughly explore the aspects of a choice context that influence otherregarding behavior. 
In both experiments, each individual subject makes all allocation choices, which allows us to observe individual-level differences in generosity across contexts. It also means that we can study how well an individual's generosity in one context predicts her generosity in other contexts, to understand better whether a preference for generosity or equality can describe an individual's behavior in multiple domains.

We focus on two primary questions. First, how does generosity change across contexts? In monetary Dictator-game experiments, the typical result involves most people sharing nothing, with the remainder divided between sharing half of the total endowment or intermediate amounts, resulting in a mean amount shared of around $25 \%$ of the total endowment (for reviews, see Camerer, 2003, Chapter 2; and Cooper and Kagel, forthcoming). A priori, then, one might expect to obtain a similar result to money when considering allocation in other contexts. For example, in allocating harm: most people give all the harm to the other party, slightly less divide the harm equally, and on average, around $75 \%$ of the harm is allocated to the recipient, thus demonstrating a mean generosity of about $25 \%$. This yields our primary null hypothesis: generosity will be similar across monetary and non-monetary contexts.

However, evidence from psychological studies indicates that this may not be the case. Several studies explore generosity in varied choice contexts (see, for example, Batson et al., 1988). In contrast with reasonable extrapolation from monetary experiments, these psychological studies generally yield a different impression of human generosity, whereby people often care as much about others as they do about themselves, or even care about another person more than themselves. For example, Batson et al. (1981) studied subjects' willingness to voluntarily endure electrical shocks that had been purportedly randomly assigned to another subject. Across several experimental conditions in their first experiment, 64 percent of subjects agreed to take at least some of the shocks and, 
overall, subjects took an average of 4.3 out of 8 shocks for themselves. Batson et al. (1983) also find that subjects are often willing to take approximately half or more of the shocks.

While many features change between contexts involving the allocation of money (as in economic Dictator experiments) and harm (as in Batson's experiments purportedly involving electric shocks), one potentially important dimension is the distinction between monetary and nonmonetary allocations. There is evidence that money has distinct and unique effects on human behavior. For example, Lea and Webley (2006) note that money may exert unique motivational influences in humans, which they compare to the effect of addictive drugs, that lead money to acquire greater value than that afforded by its instrumental uses. Consistent with the idea that money somehow leads to very different behavior, Vohs, Mead and Goode (2006) found that priming participants with money (for example, by unscrambling phrases containing words such as "high paying salary") led to self-sufficient and self-regarding behavior in terms of wanting less help from others, giving less help to others, and preferring distance from others. Further, DeVoe and Iyengar (2010) found that subjects rated hypothetical employee performance bonuses that rewarded employees unequally as much more fair, when the bonus involved money (or redeemable reward points) than when it involved time (vacation days) or food. Thus, people may behave in a uniquely selfish manner with money compared to other resources, yielding our primary alternative hypothesis: generosity will be greater in nonmonetary contexts than in monetary ones.

Second, we ask, is there a relationship between an individual's monetary and non-monetary allocations? The idea of a social preference type, present in many models (Fehr and Schmidt, 1999; Bolton and Ockenfels, 2000; Andreoni and Miller, 2002), might suggest that monetary and non-monetary generosity are generated by the same social preference structure. For example, Andreoni and 
Miller (2002) found that subjects had rationalizable preferences that fell into one of three preference types: selfish, utilitarian, or Leontief. Fehr and Schmidt (1999) model other-regarding behavior as motivated by a preference for equality, which might suggest that those who act to mitigate inequality when they have greater wealth should also act to reduce other kinds of inequality.

\section{Experiment One}

To explore the above questions we conducted a laboratory experiment using human participants. In the experiment, each participant made two allocation decisions: a division of money (\$6) and a division of a harmful experience (putting one's hand in ice water for 60 seconds). We varied the order in which participants made the two decisions.

\section{A. Experimental Design}

Fifty-four pairs of participants from the Pittsburgh community were recruited from the Center for Behavioral Decision Research subject pool. Each session had from ten to eighteen participants. Participants were randomly assigned sequential ID numbers that were unknown to other participants. Twentysix of the dictators (48 percent) were female, and twenty-six of the dictators completed the money allocation first, while the remainder completed the harm allocation first.

Initial instructions were read aloud to all participants (see Appendix 1 for all instructions). Subjects were told that they would be paid $\$ 5$ in cash at the end of the experiment, and that they might also receive an additional sum of money in cash at that time. Participants were informed that they would be split into two rooms, based on whether they had an odd or even participant ID number, and that each odd-numbered participant (dictator) would make a decision that would affect an even-numbered participant (recipient), but that even-numbered participants 
would not make any choices that affected the odd-numbered participants. They were asked not to communicate with others and to raise their hand if they had any questions during the experiment. All participants were assured that their choices throughout the experiment would be anonymous.

The even- and odd-numbered participants were then taken into separate rooms. After participants were separated they were instructed to carefully read the informed consent document. The consent ensured that no participant had any prior medical issues, such as frostbite, that would interfere with their participation in the experiment. ${ }^{3}$

There were two main choice tasks completed by dictators: an allocation of \$6 (money) and an allocation of 60 seconds of ice-water immersion (harm). Both dictators and recipients received detailed instructions describing both of the allocation tasks. An experimenter, who was unaware of the experimental hypotheses, guided the dictators through the instructions by reading them aloud and asking for any questions. Dictators first received instructions for one of the two tasks, money or harm, made decisions in that context, and then received instructions for the other context. Dictators were told that they would make two decisions, and that only one would count based on the outcome of a fair coin flip.

In the money allocation choice, dictators divided $\$ 6.00$, in 50-cent increments, between themselves and their paired recipients. If the money task was selected at the end of the experiment, then the paired recipient was informed about the money shared with him or her by the dictator, and paid this amount in cash. The dictators received the remaining payment in cash privately.

In the harm allocation choice, dictators divided 60 seconds of time spent with a hand immersed in ice water, at a temperature of 3-5 degrees Celsius, in 5second increments. Prior to completing this allocation decision, dictators were

\footnotetext{
${ }^{3}$ An additional participant, upon reading the informed consent, decided to discontinue his participation. This participant was a dictator, whose matched receiver is also excluded from the data.
} 
called one-by-one into a separate room and submerged their hand in a bucket of ice water for 5 seconds. They were told that recipients would similarly experience a 5-second trial immersion. This was done to ensure familiarity with the discomfort of the experience. ${ }^{4}$ Dictators then privately completed their allocation decisions. They were informed that if the harm choice were selected to count at the end of the experiment, the associated dictator and recipient would separately experience the specified amount of ice-water immersion determined by the dictator's allocation choice.

At the end of the experiment, after making both the allocation decisions for money and harm, dictators completed a second-price auction in which the lowest bidder in a session would receive a payment (determined by the amount bid by the second-lowest bidder) to immerse his or her hand in ice water for 60 seconds. We use the bids in this auction to determine each subject's minimum Willingness to Accept (WTA) for the ice-water-immersion experience, and to control for possible heterogeneity in the disutility from this experience.

In the other room, a different experimenter guided receivers (evennumbered participants) through their instructions. Receivers were informed about the two allocation decisions being completed by dictators, one at a time. After learning about the harm task, receivers experienced 5 seconds of immersing their hand in ice water and then participated in the second-price auction to determine their minimum WTA for 60 seconds of ice-water immersion. Receivers also provided expectations about the dictators' allocation decisions, though they were not provided any monetary incentives for accuracy.

After all of the dictators completed their choices, the second-price auction, and a follow-up questionnaire, the experimenter flipped a fair coin and allowed each dictator to call the coin in the air. Dictators were told ahead of time

\footnotetext{
${ }^{4}$ In a study by Mitchell, MacDonald, and Brodie (2004) found the smallest differences in pain tolerance between men and women at 3 degrees Celsius. Most men and women rated this experience between a 45 and 90 on a visual analog scale ranging from 0 (no discomfort) to 100 (worst discomfort possible).
} 
that if they called it correctly the money allocation would count and, otherwise, the harm allocation would be enforced. A record of each dictator's decisions and the result of the coin flip was transferred to the receivers' room, and the receivers were given the allocations of either money or ice-water immersion produced by their paired dictators. Dictators were then taken into a separate room, one at a time, to receive their allocations. For money allocations, participants were paid immediately in cash. For harm allocations, participants submerged their hand into an insulated water cooler containing water and ice maintained at a temperature between 3-5 degrees Celsius. Time was calculated using a digital stopwatch. In the case of receivers, each individual was shown the result of her assigned dictator's choice and the outcome of the coin flip, and received the requisite allocation in the presence of the other receivers so that they could leave quickly. The anonymity of the dictator was not compromised by this procedure.

\section{B. Results}

For the analysis below, we transformed each allocation decision made by a dictator into a Generosity Index $\left(G_{\mathrm{i}}\right)$. For the money allocation, $G_{\mathrm{i}}{ }^{\mathrm{M}}$ is equal to the proportion of the total monetary endowment that was given to the other participant. For the harm allocation, $G_{\mathrm{i}}{ }^{\mathrm{H}}$ is equal to the proportion of the total time of ice-water immersion kept for oneself. ${ }^{5}$

Consistent with our primary alternative hypothesis, we find that dictators were, on average, more generous in their nonmonetary divisions of harm than when dividing money, with mean $G_{\mathrm{i}}{ }^{\mathrm{H}}=0.48(S D=0.28)$ and mean $G_{\mathrm{i}}{ }^{\mathrm{M}}=0.30$

\footnotetext{
${ }^{5}$ Prior to conducting this experiment, we ran a small pilot study. Procedures were similar except for small differences in methods: each participant was both a receiver and a dictator, participants did not experience the cold water before making their allocations, and willingness to accept was not elicited. Twenty four members (11 females) ages 18-61 years ( $M=27$ years, $S D=10.9$ years) of the Pittsburgh community were recruited for this experiment entitled "Decision Study" using the Center for Behavioral Decision Research subject pool. Most of the participants (58\%) took more than half of the money for themselves with the remainder splitting the money equally. In contrast, a minority (29\%) gave the other person more than half of the pain; most (58\%) split the pain equally; and a few (13\%) took more than half of the pain on themselves. The data were consistent with our alternative hypothesis: participants were on average more generous in their divisions of time putting one's hand in ice water $(M=0.48, S D=0.16)$ compared to their divisions of money $(M=0.34, S D=0.19)$.
} 
$(S D=0.20)$. This difference is significant in a paired-samples $t$-test for differences in means $(t(53)=4.27, p<0.0001)$.

Figure 1 presents the empirical cumulative distributions of $G_{\mathrm{i}}$ for each condition. While the proportion of entirely selfish $\left(G_{\mathrm{i}}=0\right)$ behavior is similar between conditions (money: 17\%, harm: 13\%), as is the proportion of people distributing the money or harm equally $\left(G_{\mathrm{i}}=0.5\right.$, money: $35 \%$, harm: $\left.41 \%\right)$, there is more generous behavior in the harm context than for money. For example, while only one person (2\%) gave more than half the money, 16 people (30\%) kept more than half the harm.

Figure 2 presents the joint distribution of generosity in the money and harm contexts, by subject. The horizontal axis corresponds to possible degrees of generosity in the sharing of harm $\left(G_{\mathrm{i}}^{\mathrm{H}}\right)$, while the vertical axis corresponds to generosity in the sharing of money $\left(G_{\mathrm{i}}^{\mathrm{M}}\right)$. The size of each marker indicates the number of subjects represented by that data point. The two most frequent joint outcomes correspond to subjects dividing equally in both contexts $\left(G_{\mathrm{i}}^{\mathrm{H}}=G_{\mathrm{i}}^{\mathrm{M}}=\right.$ $0.5,12$ cases or 22 percent) and to subjects behaving completely selfishly in both contexts $\left(G_{\mathrm{i}}^{\mathrm{H}}=G_{\mathrm{i}}^{\mathrm{M}}=0,6\right.$ cases or 11 percent $)$.

Looking at the individual behavior presented in Figure 2, we find that twenty-five (46\%) subjects were more generous when allocating harm than money, twenty-two (41\%) made the same decision both times, and only seven $(13 \%)$ were more generous for money than harm. A chi-square test indicates that these data are unlikely given a null-hypothesis distribution of equal proportions $\chi^{2}(2)=8.44, p=0.015$.

The fact that 22 of 54 subjects behaved consistently across contexts means that the change in behavior among those subjects who do not behave consistently is larger than our earlier aggregate analysis suggests. Figure 3 presents the cumulative empirical distributions of generosity, only for those subjects whose generosity changed between the two contexts (referred hereafter as "inconsistent" 
subjects). In comparison with Figure 1, it is clear that the difference in behavior is substantially larger. When looking only at this subsample, mean $G_{\mathrm{i}}^{\mathrm{H}}=0.60(S D=$ $0.25)$ is over twice as high as mean $G_{\mathrm{i}}{ }^{\mathrm{M}}=0.29(S D=0.18)$.

Combining the above observations yields our first main finding regarding the relative degrees of generosity in monetary allocations and those involving harm:

\section{Result 1: Dictators are typically more generous when allocating} harm than when allocating money.

Thus, consistent with our alternative hypothesis, we find a different pattern of behavior in the domain of nonmonetary allocations of harm than in the standard monetary Dictator game. This suggests that identifying the degree of generosity in monetary domains may not allow a direct extrapolation to generosity in other, non-monetary, contexts such as the allocation of harm. The fact that generosity is greater in the allocation of harm is consistent with results from earlier psychological studies, in which people were highly generous in distributing harm.

Of course, one important consideration in interpreting the above result is that we have assumed that immersing one's hand in ice water is painful, rather than enjoyable, to participants. There are at least three reasons to think that this is, in fact, the case. First, if participants instead found immersion enjoyable, then we would interpret generosity as sharing the immersion experience and would expect the distribution of $G_{\mathrm{i}}^{\mathrm{H}}$ to approximate the distribution of $1-G_{\mathrm{i}}^{\mathrm{M}}$. That is, we would expect dictators to keep a majority of the enjoyable experience for themselves or split it equally, with very few opting to give more of the enjoyable experience to the recipient. Inspection of Figures 1 and 2 reveals that this is not what we observe. For example, of the fifty-four dictators, only one gave more than half of the money, while sixteen gave more than half the immersion time. 
Thus, the overall distribution is inconsistent with the notion that dictators simply keep more time because they believe it is enjoyable.

A second, more direct, test of whether dictators find the ice water enjoyable is the extent to which they require compensation for the experience of immersing their hand in ice water. We obtained this measure at the end of the experiment via a second-price auction. If dictators believed the ice-waterimmersion task to be enjoyable, then we would expect them to require zero compensation for the experience. Only two dictators gave WTA values of $\$ 0$, indicating that for an overwhelming majority of dictators the experience was aversive. Dictators had a mean minimum Willingness to Accept (WTA) in dollars for immersing their hands in ice water for sixty seconds of $5.91(S D=7.92)$, which differs significantly from zero $(t(53)=5.48, p<0.001)$ and a median WTA of $4.25 .^{6}$

Third, the relationship between WTA values and generosity in allocating harm is weak, at best, and does not account for the difference in generosity between contexts. Figure 4 shows the relationship between an individual dictator's WTA and that individual's generosity in the allocation of harm. Participants who viewed the ice water experience as more aversive, as indicated by a greater WTA, were only slightly less generous in their allocations of harm, as the OLS coefficient obtained in a regression of $G_{i}^{\mathrm{H}}$ on WTA is -0.0072 (s.e. = $0.0047)$ and is not statistically significant, $t(52)=1.52, p=0.134 .^{7}$

Table 1 presents the mean WTA of subjects exhibiting different degrees of generosity when allocating harm. We exclude the one outlier with a WTA of

\footnotetext{
${ }^{6}$ Consistent with earlier research (Mitchell, MacDonald, and Brodie, 2004), we find that men (mean WTA $=4.45, \mathrm{SD}=$ 5.24) find the experience less aversive than women (mean WTA $=7.49, \mathrm{SD}=9.80$ ), though this difference is not statistically significant $(\mathrm{t}(52)=1.42, \mathrm{p}=0.16)$. Measured generosity in the harm context does not differ significantly between men $\left(\right.$ mean $\left.\mathrm{G}^{\mathrm{H}}=0.52\right)$ and women $\left(\right.$ mean $\left.\mathrm{G}^{\mathrm{H}}=0.45, \mathrm{t}(52)=0.96, \mathrm{p}=0.34\right)$. The WTA values for receivers were also similar to those of dictators, with a mean of $6.93(\mathrm{SD}=10.50)$ and median of 4.88 . The $95 \%$ confidence interval for the difference in means includes zero, $t(106)=0.57, p=0.57$, indicating no difference in the undesirability of the immersion experience between dictators and recipients.

${ }^{7}$ The relationship between WTA and $\mathrm{G}_{i}^{H}$ is even weaker when the one outlier $(\mathrm{WTA}=\$ 50)$ is removed. In this case, there is a small positive, but statistically insignificant, correlation between WTA and $G_{i}^{\mathrm{M}}$.
} 
$\$ 50$. The sixteen participants who were very generous in their allocations of harm $\left(\mathrm{G}_{i}{ }^{H}>0.5\right.$, that is, kept more than half of the time for themselves) provided only slightly lower WTA values than those subjects who either divided the time equally or who gave more than half the time to the recipient. None of the differences in WTA across the three columns in Table 1 are significantly different in pairwise $t$-tests ( $p>0.46$ in all comparisons).

Thus, from the above analysis and results we can conclude that most dictators found the ice-water-immersion experience aversive. Moreover, the degree to which they did so had little relationship with their decisions of how to allocate harm between themselves and the recipient.

To more precisely test for differences between the monetary and harm allocations, we conducted the regressions reported in Table 2. In each model, the measured generosity $\left(\mathrm{G}_{i}{ }^{H}\right.$ or $\left.\mathrm{G}_{i}{ }^{M}\right)$ is the dependent variable. The primary explanatory variable is whether the allocation involved money (0) or harm (1). The first two models account for individual differences by including subject fixed effects. To account for the role of individual characteristics in generosity, the third model does not include fixed effects, but instead introduces individual-specific explanatory variables, including the order in which the dictator saw the two choices (either money then harm (0) or harm then money (1)), an interaction term between context and order, individual-specific controls for gender, age, and valuation of the ice-water immersion experience (WTA). Finally, Model 3 also includes the interaction between WTA and harm context, to account for the fact that WTA for the harmful experience may partly account for allocation behavior. This model also clusters standard errors by subject.

Across all specifications, we find that generosity is greater in the harm context, and that this is robust to order effects and when controlling for individual characteristics. Moreover, consistent with our earlier observation, the size of the difference is much larger for inconsistent subjects. Finally, while Model 3 appears 
to show that subjects who are willing to accept less for ice-water immersion experience also appear more generous, this is driven mainly by the one WTA outlier of $\$ 50$ - omitting this observation makes the coefficient on the Harm context X WTA interaction statistically insignificant. Thus, we strengthen the support for Result 1. Consistent with the alternative hypothesis, subjects appear to be much more generous in the allocation of harm than in allocating money, even after accounting for their valuation of harm.

We now turn to our second research question, which deals with the extent to which there is a relationship between an individual's generosities across the two allocation contexts. Figure 2 reveals little apparent relationship between a dictator's allocation of money and harm for most subjects. As we note above, only twenty-two "consistent" subjects (41\%) made the same decision for harm and money. Moreover, the correlation between generosity for harm and money is not statistically significant $(r=0.143, t(52)=1.044, p=0.301) .{ }^{8}$ Thus, we have our second main result:

Result 2: We find no significant relationship between an individual's generosity in allocating harm and money.

This result suggests that a single social preference cannot account for the majority of individual subjects' behavior in the two contexts. Instead it appears that most subjects approach the two decisions differently, in a way that is not easily predicted across domains.

\section{Experiment Two}

Our second experiment extends the design of Experiment 1 both to determine the robustness of our findings and also to obtain a better understanding

\footnotetext{
${ }^{8}$ The correlation was also not significant using non-parametric correlations: Spearman's $\rho=0.056, p=0.69$.
} 
of what elements of the money-versus-harm allocation contexts drive the differences in observed generosity. To test robustness, we use a different group of subjects, employ slightly different procedures and, most importantly, use a different aversive experience in the allocation of harm.

To understand better what drives the differences in Experiment 1, we separate the effects of monetary versus non-monetary allocations from the effects of allocating things that are good (that is, resources with a positive marginal Willingness-to-Pay (WTP)) versus bad (that is, resources with positive marginal Willingness-to-Accept (WTA)). Note that, in Experiment 1, we varied both

dimensions simultaneously, in that the allocation choices for money were monetary and good, while the allocation choices for harm were non-monetary and bad.

\section{A. Experimental Design}

Experiment 2 includes the kinds of allocation choices from Experiment 1 - money versus harm - but also extends the studied contexts in a 2 X 2 design that varies two features of the context. The first feature involves varying whether the allocation is monetary or non-monetary, while the second involves whether the allocation involves a positive or negative change from the status quo. More precisely, we considered four contexts:

In the Monetary-Positive $(M+)$ allocation, dictators allocated a gain of $\$ 10$, in $\$ 1$ increments, between themselves and their paired recipients. In this way, our Dictator game more closely mirrors the traditional $\$ 10$ allocation amount used in other Dictator game experiments, in contrast with the $\$ 6$ allocations in Experiment 1.

In the Monetary-Negative (M-) allocation, dictators allocated a loss of $\$ 10$, in $\$ 1$ increments. The principal difference between these first two treatments, 
therefore, dealt with whether the units allocated increased or decreased subjects' earnings beyond the participation payment.

In the Non-monetary-Positive $(\mathrm{NM}+)$ allocation, dictators allocated ten units of diverse consumption goods worth approximately $\$ 1$ each. Subjects were shown a diverse set of goods, arranged on a table in a manner that allowed easy inspection. The goods included snack items (including healthy fruit and vegetable options), beverages, personal care items, and assorted sundries. ${ }^{9}$ All of the items had retail values of approximately $\$ 1$. Subjects were provided with a bag to easily transport any goods that they obtained during the experiment.

In the Non-monetary-Negative (NM-) allocation, which is comparable to the harm condition from Experiment 1, dictators allocated time experiencing an aversive stimulus. In this case, the aversive experience involved a total of ten minutes - to be allocated in one-minute units - listening to a loud aversive tone.

Noise has been used as an aversive stimulus in many psychological and economics experiments (for example, Bushman and Baumeister, 1998; Ariely and Zauberman, 2000; Schreiber and Kahnmean, 2000; Ariely, Loewenstein and Prelec, 2003). Noise is easy to replicate across participants and time, has little or no satiation/sensitization, and has a good (monotonic) psychophysical relationship to annoyance (Schrieber and Kahneman, 2000). Our noise (a sinusoidal waveform

\footnotetext{
${ }^{9}$ The specific goods were: Kirkland Dry and Roasted Almonds, Kirkland Roasted and salted extra crunchy peanuts, Kirkland Roasted and Salted Cashews, Snickers bars, original Skittles, original Starburst, regular and nut M\&Ms, original Three Musketeers bars, Milano original cookies, Pepperidge Farm mini chocolate chunk Nantucket cookies, Goldfish crackers original cheddar, and Goldfish crackers flavor blasted, Hershey's original milk chocolate bars, Hershey's milk chocolate bars with almonds, Reese's original peanut butter cups, Kit-Kats, Mini-Oreos, Nutter Butter bites, Ritz-bits crackers, Mini Nilla wafers, Peanut butter Ritz-bits, mini Chips Ahoy, Kebler Fudge Shoppe fudge grammes, Keebler fudge shoppe fudge stripes, Cheese-itz, Cheetos crunchy, Lays barbecue potato chips, original Fritos, Cool Ranch Doritos, classic Lays potato chips, Nacho Cheese Doritos, Lays sour cream and onion potato chips, Minute-Maid apple-juice box, Minute-Maid mixed berry juice box, Minute-Maid lemonade juice box, Sun-Maid cranberry boxes, Fruit-2-day pomegranate blueberry bottle, Fruit-2-day pineapple banana, Fruit-2-day raspberry lemon, Fruit-2-day strawberry orange, Fruit-2-day mango peach, Giant Eagle Nature's Basket organic original popcorn, Sun-Maid raisins boxes, Bolthouse farms baby-cut carrots (5-pack), Giant Eagle purified water $240 \mathrm{ml}$ bottles, fresh green apple, fresh orange, and fresh red apple, fresh banana, Mountain Dew, Coca-Cola, Sprite, Wintergreen Altoids (50 mints); Up and Up Instant Hand Sanitizer (2 ounces); Johnson and Johnson Reach Floss Mint-Waxed and CleanBurst (55 yards); Dove Cucumber and Tea Scent Deodorant (.05 ounces); Degree Cool Rush Deodorant (25 ounces); Dove Powder Deodorant (.05 ounces); Caress White Peach and Blend of Silk Blossom (.02 ounces); Garnier Fructis Daily Care Shampoo (1.7 ounces); Papermate Eagle Ball Point Pens (10 pack); Dr. Fresh Daily Travel Kit (tooth brush and tooth paste); Mini Squirt Guns (3 pack); Orbit Gum Bubblemint, Cinnamint, Strawberry Remix (14 pieces); Tic-Tac Orange and Freshmint (1 ounce); Lance Fresh Captain's Wafers, Wholegrain Cheddar Cheese Crackers, Peanut Butter Toasty Crackers, Peanut Butter Toast Cheese Crackers.
} 
at $2083 \mathrm{~Hz}$ and $90 \mathrm{~dB}$ ) was chosen to be aversive to most participants without endangering hearing loss. ${ }^{10}$

Forty-four pairs of participants from the Pittsburgh community were recruited for an experiment entitled "Allocation Study" using the Center for Behavioral Decision Research subject pool. Each session had from ten to eighteen participants, each of whom were randomly assigned a sequential ID number that was unknown to the other participants. To enable the Monetary-Negative condition, all participants were paid $\$ 16$ in cash at the beginning of the experiment, from which the allocated losses would be subtracted were this allocation to count. As in Experiment 1, following the assignment of ID numbers, subjects were divided into two groups, told that one group would make allocation decisions that would affect both groups, and taken to separate rooms.

Each dictator made all four of the above allocation decisions, the order of which was randomized by subject. Once subjects were in separate rooms, they were seated at computer terminals and asked to put on headphones. All instructions were available on the computer screen and were also pre-recorded and played through headphones ${ }^{11}$ at $70-75 \mathrm{~dB}^{12}$. All participants were forced to listen to the recording for the entire duration before proceeding to the response options. Subjects were told that at the end of the experiment, one of the four allocation decisions for each dictator-receiver pair would be randomly chosen (with equal probability) and fully executed by the experimenter.

\footnotetext{
${ }^{10}$ A meta-analysis of annoyance ratings by sound level indicate that close to $100 \%$ of people are highly annoyed by the 90 $\mathrm{dB}$ level (Maris, 2008), though even maximum non-damaging (115 dB) noise is less aversive than typical shock levels used in psychological research (Campbell and Bloom, 1965). In terms of permanent hearing loss, it is known that regular exposure at $110 \mathrm{~dB}$ or more for over a minute can cause permanent damage, while at $90 \mathrm{~dB}$ such damage requires repeated eight-hour exposure (OSHA, 2011; NIDCD, 2011). Thus, a $90 \mathrm{~dB}$ noise is very likely to be experienced as aversive but not likely to cause permanent hearing loss even at ten minutes of exposure.

${ }^{11}$ Headphones for the receivers were GE digital stereo headphones, linked through two Belkin 5-way splitters. Each splitter was boosted through a Boostaroo T613-BNC 3 channel splitter and amplifier. Headphones for dictators were one Sony MDR-V150, three CA-HE200, two GE digital stereo headphones, and two Maxell Studio Series. Prior to the experiment starting, all headphones were calibrated to a tone at $90 \mathrm{db}$. The volume was adjusted on the computer itself, as headphone volume controls were set to maximum volume and taped to prevent tampering.

${ }^{12} \mathrm{All} \mathrm{dB}$ measures throughout were done at $0 \mathrm{~cm}$ from the headphone source using a Radio-shack digital sound-level meter SKU: 33-2055. As participants' ears are slightly further away than $0 \mathrm{~cm}$, they experienced a tone slightly softer. However, we used the $0 \mathrm{~cm}$ measurement because it is easily replicable.
} 
The instructions were generally similar to those in Experiment 1. During the instructions for the Non-monetary-Negative allocation choice, the tone automatically played for five seconds to provide subjects familiarity with the experience. All participants completed second-price auctions to elicit their minimum WTA for one additional minute of the tone and their maximum WTP for one additional item from the non-monetary goods.

\section{B. Results}

As in Experiment 1, we transformed each allocation decision made by a dictator into a Generosity Index $\left(G_{\mathrm{i}}\right)$. The indices for each context are: MonetaryPositive $\left(G_{i}^{M+}\right)$, Monetary-Negative $\left(G_{i}^{M-}\right)$, Non-monetary-Positive $\left(G_{i}^{N M+}\right)$, and Non-monetary-Negative $\left(G_{i}^{N M-}\right)$.

We find little evidence of presentation order effects. For example, if we regress the generosity in each context on the position in which that allocation decision took place in the experiment, all four coefficients are small $(|\beta|<$ $0.024)$ and statistically insignificant ( $\mathrm{p}>0.44)$. Therefore, we pool the data from different choices in most of our analysis, and include controls for order in the regressions.

Figure 5 shows the cumulative empirical distribution for the generosity in each context. Table 3 provides summary statistics of the degree of generosity across different contexts.

We again see that generosity varies across contexts. Figure 5 and Table 3 confirm the main result from Experiment 1, that generosity is greater in the allocation of harm than in allocations of positive wealth $\left(G_{i}^{N M-}>G_{i}^{M+}\right)$, though the difference in means (0.075) is smaller than in Experiment $1(\mathrm{t}(43)=1.738, \mathrm{p}=$ 0.089). Moreover, while only 38 percent of subjects exhibited generosity of at least 0.5 when making a positive monetary allocation, 55 percent did so when 
allocating harm. Thus, while not as strong in magnitude as our result in Experiment 1, we again see that subjects are more generous when allocating harm than when allocating monetary gains.

The larger difference in Experiment 2 appears when comparing Monetary and Non-monetary allocation choices. Subjects are more generous in the Nonmonetary domains, where mean generosity, combined across positive and negative allocations $\left(G_{i}^{N M}=0.46\right)$, is considerably higher than in the positive and negative allocation of money $\left(G_{i}^{M}=0.29\right)$.

Table 4 reports regressions that explore how generosity changes across contexts. The dependent variable is the generosity exhibited in a particular context, and the first three explanatory variables identify the varying contexts, relative to the omitted context, Monetary-Positive. Models 1 and 5 include all subjects, with the former accounting for individual differences through subjectspecific fixed effects and the latter accounting for individual-specific variation through controls and clustered standard errors. In both Models 1 and 5, the largest difference, both in terms of magnitude and statistical significance, corresponds to the effect of Non-monetary, which accounts for a 0.23-0.29 increase in generosity. $^{13}$

Ten of the 44 subjects exhibited identical generosity across all contexts. Nine of these subjects allocated evenly across all decisions $\left(G^{i}=0.5\right)$, while the remaining one always acted entirely selfishly $\left(G^{i}=0.0\right)$. Thus, as in Experiment 1, an overwhelming majority of subjects who were consistent were either highly equitable or completely selfish. Model 2 omits the consistent individuals, finding as in Experiment 1 that the treatment differences are somewhat larger for inconsistent subjects.

\footnotetext{
${ }^{13}$ To test the difference in generosity between the positive monetary allocation $\left(\mathrm{G}^{\mathrm{M}+}\right)$ and the allocation of harm $\left(\mathrm{G}^{\mathrm{NM}-}\right)$, as in Experiment 1, we test the restriction that the first three coefficients in Model 1 sum to zero. As our earlier analysis suggests, this restriction is rejected at a similar level of significance $(\mathrm{F}(1,128)=3.73, \mathrm{p}=0.056)$. We can also limit Model 1 to only those two conditions, and include a coefficient measuring the difference in generosity, which yields similar results (coefficient $=0.076, \mathrm{p}=0.088)$.
} 
Our measure of generosity rests on the assumption that the tone is aversive and the snacks are desirable. We can evaluate the participants' willingness to pay (WTP) for one additional unit of the consumption good and willingness to accept (WTA) for one additional minute of listening to the tone, to test the assumption that both are different from zero. For the aversive experience, zero participants gave WTA values of $\$ 0$ for the sound, indicating that all participants found the experience aversive. The elicited values ranged from $\$ 0.19$ to $\$ 30.50$, with a mean minimum WTA for dictators of $5.38(S D=6.33)$. Thus, we can be reasonably confident that this experience was indeed aversive.

For the consumption goods, however, ten subjects (23\%) gave WTP values of $\$ 0$ for one additional unit. Dictators had a mean maximum Willingness to Pay (WTP) in dollars for one additional good of $0.46(S D=0.52)$. Thus, unlike the harmful and aversive experiences in our experiments, there is a potential problem that the non-monetary good is not highly valued by subjects, which might at least partly account for some of the increased generosity in this context. The data indicate that this explanation does not fully account for our results.

First, Figure 6 plots the relationship between generosity in the Nonmonetary-Positive context and the subsequent willingness to pay for the goods allocated in this context. While there is a modest negative relationship (correlation $=-0.12)$, it is not statistically significant. Thus, the increased generosity does not appear entirely driven by subjects who simply do not value the consumption good.

Second, consider the robustness of our results to omitting subjects who do not appear to value the marginal unit of the non-monetary good. Appendix Figure A1 shows how Figure 5 changes if we omit those subjects with a WTP of zero. While, relative to Figure 5, this decreases the frequency of highly-generous allocations, the general qualitative aspects of the data hold. Repeating the analysis in Table 4 omitting those subjects (see Model 3) finds smaller, but qualitatively 
similar and statistically significant effects. In addition, to see if our results hold under even more restrictive assumptions, we repeat the above two analyses using only those subjects who provide WTP values of at least $\$ 0.50$. Using these 18 subjects, we again construct the analogous graph to Figure 5 (Figure A2 in the Appendix) and repeat the regression analysis (Model 4, Table 4). The data again strongly support a difference between monetary and non-monetary allocations.

Taking all of the above findings together, we obtain the following result:

\section{Result 3: Dictators are typically more generous in non-monetary allocations than in monetary allocations.}

This result complements and refines Result 1, by showing that the key difference between allocations of money and harm in Experiment 1 appears to be the monetary versus non-monetary dimension, rather than a difference between positive and negative allocations.

We now consider the additional question of whether one can predict a subject's generosity in one context by her behavior in another. Table 5 presents the correlations between observed degrees of generosity in the four contexts

(asterisks $\left({ }^{* * *}\right)$ denote a correlation statistically significant at $\mathrm{p}<0.01$ ). As the table reveals, only the two monetary allocation decisions had a high (and statistically significant) correlation. Thus, one can predict how well an individual will share in one monetary context by how much that individual shares in another monetary context. But, this predictive ability does not extend to other contexts.

To get a better sense of how individual choices varied across contexts, we conducted exploratory analyses of co-variation in choices in two ways. First, we conducted a principal components analysis of the four generosity measures. We retained the two factors that explained the greatest variance, which jointly account for 74 percent of the variance. Each of these factors has an eigenvalue of at least 0.99. As seen in Table 6, these two factors roughly correspond to monetary and 
non-monetary allocations. Thus, a simple division of our contexts, into monetary and non-monetary, explains a great deal of the observed behavior

We also examined the relationship between the participants' four decisions using cluster analysis. This approach attempts to determine whether there exist different patterns of decisions across the four contexts that cannot be captured purely by linear regression. We employed k-means clustering in Stata. Two clusters emerged, with approximately half the participants falling into each cluster. As seen in Figure 7, subjects in Cluster $1(n=21$, circles) gave more for non-monetary resources compared to monetary resources. These participants are generally more likely to be along the boundary of the graphs for monetary choices. Cluster 2 subjects $(n=23$, stars $)$ were generally egalitarian across all choices, splitting each resource equally. These participants can be identified as usually on the interior (near the center) of the graphs.

Figure 8 shows the mean amount of generosity, in each context, for the two clusters. Consistent with our above interpretation of the two clusters, subjects in Cluster 1 exhibit high sensitivity to context, and therefore drive most of the differences in generosity that we observed. These subjects are not very generous in monetary allocations, but significantly more generous in non-monetary allocations. Subjects in the second cluster, on the other hand, are generally egalitarian across all four contexts.

\section{Discussion}

Economists have devoted considerable attention to studying generosity in monetary allocations. However, notwithstanding the importance and prevalence of other-regarding behavior in individuals' decisions regarding non-monetary goods, and in particular the allocation of harm, there is a surprising lack of carefully controlled economic studies in this domain. Here, we explored this topic by extending the existing experimental Dictator-game paradigm into this 
understudied realm. The reliance on this workhorse of experimental economics allows us to explore allocation decisions across contexts in a controlled and wellunderstood framework. It also allows us to calibrate our results to earlier work, demonstrating that the generosity observed in our monetary contexts is similar to that found in previous laboratory research.

While allocations of money were similar to what has been observed in the literature (Camerer, 2003, Chapter 2, and Cooper and Kagel, forthcoming), we found generosity to be considerably higher in non-monetary contexts. Participants in Experiment 1 were substantially more generous when allocating harm compared to money. Similarly, while in Experiment 2 monetary allocations differed little based on whether they were positive or negative, generosity in nonmonetary allocations was again considerably higher. Pooling data across both experiments, we estimate a mean generosity that is considerably higher in nonmonetary $\left(G_{i}^{N M}=0.47\right)$ than monetary $\left(G_{i}^{M}=0.29\right)$ contexts.

The observation that individuals are relatively generous when allocating harm is consistent with the small number of related psychological experiments that have been conducted in different domains (Batson, et al., 1988; Schaller and Cialdini, 1988; see Batson, 1987 for a review). However, these prior studies are not directly comparable to the large literature on monetary allocations using the Dictator game, and have large methodological differences, including a lack of anonymity and real outcomes, deception, and exogenous empathy inductions. Given that we also observe high generosity in harm allocation behavior using the more abstract and sterile methodology and environment employed in experimental economics, we support the case that such generous behavior in the context of harm is relatively stable and not as sensitive to the social factors that influence monetary allocations (such as anonymity, see Hoffman et al., 1994).

It is also possible that the imposition of harm on another might lead to different cognitive processing. When one fails to give money to another person, 
this may be perceived as not directly harming them. However, when one imposes pain on someone, this may be perceived as direct harm, and there is some evidence that people prefer indirectly harming others over directly harming them (Royzman and Baron, 2002). Thus, behavior may be driven by a simple rule of "do no harm," which leads to asymmetric behavior across the money and harming domains.

Importantly, our main result also addresses some recent findings that suggest behavior in standard monetary Dictator games may overstate the degree of generosity outside the laboratory (Levitt and List, 2007; List, 2007; Bardsley 2008). This conclusion is suggested by experiments that change features of the Dictator game to yield less generosity. In contrast, we find that a version of the Dictator game that changes the resource allocated yields considerably higher generosity without introducing other self-interested concerns such as reputation. This suggests that the vast literature on Dictator games using monetary allocations may underestimate the degree of generosity in these other naturally occurring contexts.

Our data also reveal that the link between a given individual's generosity across domains is tenuous at best. We find that the observation of generosity in one context allows for very little predictive power regarding an individual's generosity in another context. Across both experiments, when considering at least one non-monetary allocation decision, the statistical correlation between generosity in the two contexts never rises above 0.2 . We do find that subjects' behavior exhibits strong persistence between the two monetary contexts in Experiment 2, but that is the clear exception.

We also find that a minority of participants have perfectly consistent preferences across contexts. For example, in Experiment 1, 41 percent of subjects exhibited perfect consistency between the two decisions $\left(G_{i}^{M}, G_{i}^{H}\right)$, with six giving $(0,0)$, twelve giving $(0.5,0.5)$, and four more giving other amounts. In 
Experiment 2, ten participants behaved entirely consistently across all four allocation decisions, with nine allocating $(0.5,0.5)$ across all four decisions and one behaving selfishly $(0,0)$. Thus, ten of forty-four $(23 \%)$ subjects were perfectly consistent in Experiment 2. While for these subjects it is clearly easy to predict how they will allocate across contexts, it is not clear whether there is an a priori way to identify these types.

Finally, the complete set of allocation choices in our experiments seem to best be categorized along a monetary vs. non-monetary dimension. Our exploratory analysis to extract principal components and clusters from the Experiment 2 data is consistent with the idea that, at least for a large proportion of subjects, these two kinds of allocation choices are very different.

What do these results mean for theories of social preferences? At one extreme, researchers have attempted to model all social preferences under a single parametric model, meaning different contexts can be exactly equated given a few individual-specific but context-independent parameters. That is, under this approach, there is a single social preference for each person, and all otherregarding decisions for this person are predictable once this preference structure is known. We provide evidence that this approach may have limited descriptive value across contexts. At the opposite extreme, if each participant's behavior in one context provides no information about behavior in other contexts, researchers might have to create a unique model for each participant for each context. In between these two extremes, perhaps behavior in one context provides partial information about behavior in other contexts. Such a model that includes some characteristics of the individual, as well as features of the context, might prove valuable in accounting for our results and other results demonstrating instability in pro-social behavior (Krupka and Weber, 2011). 


\section{Conclusion}

We observe individuals' interpersonal allocation choices across multiple contexts. We find that generosity varies substantially across these contexts, with individuals behaving considerably more generously in non-monetary contexts, including the allocation of harm, than in those involving money. We also find that an individual's generosity is difficult to predict across contexts, with the exception of generosity in one monetary context predicting behavior in another context also involving money.

Our results present a challenge for the theoretical literature on pro-social preferences. Much of economic theorizing relies on the presumption that a single, well-specified preference function should be able to capture behavior across large swaths of choices. Here, we observed individuals who made selfish choices in the monetary domain choosing to be rather generous in the non-monetary domain, and that this relationship held for the majority of participants. Such behavior is not easily captured by a single, traditional preference function for altruism or equality, nor does it naturally arise in the various modified preference functions that have been suggested in the study of pro-social behavior.

Over the past few decades, we have built up a solid theoretical, empirical, and experimental understanding of how people make choices in the context of monetary goods. However, as we seek to understand more and more of our social world, we need to account for behavior in a variety of contexts, including those that vary in the monetary versus non-monetary consequences of individuals' actions. The work here suggests that our understanding of behavior in the former kind of context, while quite useful in and of itself, may not easily account for behavior arising in other contexts, of the latter type. Given the ubiquity and importance of choices that occur in these alternative contexts, further developing a useful theoretical and empirical understanding seems warranted. 


\section{References}

Andreoni, J., and Miller, J. "Giving According to GARP: An Experimental Test of the Consistency of Preferences for Altruism." Econometrica 70(2) (2002): 737-53.

Andreoni, J., and Vesterlund, L. "Which is the Fair Sex? Gender Differences in Altruism." Quarterly Journal of Economics 116(1) (2001): 293-312.

Ariely, D., Loewenstein, G., and Prelec, D. “'Coherent arbitrariness': Stable Demand Curves Without Stable Preferences." Quarterly Journal of Economics 118(1) (2003): 73-105.

Ariely, D., and Zauberman, G. "On the Making of an Experience: The Effects of Breaking and Combining Experiences on their Overall Evaluation." Journal of Behavioral Decision Making 13 (2009): 219-32.

Bardsley, N. "Dictator Game Giving: Altruism or Artefact?" Experimental Economics 11(2) (2008): 122-33.

Batson, C. "Prosocial Motivation: Is it Ever Truly Altruistic?" Advances in Experimental Social Psychology, Volume 20, edited by Berkowitz, L., 65-114, Boston: Academic Press, 1987.

Batson, C., Duncan, B., Ackerman, T., Birch, K. "Is Empathic Emotion a Source of Altruistic Motivation?" Journal of Personality and Social Psychology 40(2) (1981): 290-302.

Batson, C., Dyck, J., Brandt, J., Batson, J., Powell, A., McMaster, M., and Griffitt, C. "Five Studies Testing Two New Egoistic Alternatives to the Empathy-Altruism Hypothesis." Journal of Personality and Social Psychology 55(1) (1988): 52-77.

Batson, C., O'Quin, K, Fultz, J., Vanderplas, M., Isen, A. "Influence of SelfReported Distress and Empathy on Egoistic Versus Altruistic Motivation to Help." Journal of Personality and Social Psychology 45(3) (1983): 706-718.

Bénabou, R., and Tirole, J. "Incentives and Prosocial Behavior." The American Economic Review 96(5) (2006): 1652-78.

Bolton, G., and Ockenfels, A. "A Theory of Equity, Reciprocity, and Competition." The American Economic Review 90(1) (2000): 166-93.

Bushman, B., and Baumeister, R. "Threatened Egotism, Narcissism, Self-Esteem, and Direct and Displaced Aggression: Does Self-love or Self-hate Lead to Violence?" Journal of Personality and Social Psychology 75(1) (1998): 21929. 
Camerer, C. "Dictator, Ultimatum, and Trust Games." In Behavioral Game Theory: Experiments in Strategic Interaction, edited by Camerer, C. (Ed.), 43117, Princeton: Princeton University Press, 2003.

Campbell, B., and Bloom, J. "Relative Aversiveness of Noise and Shock. Journal of Comparative and Physiological Psychology 60(3) (1965): 440-42.

Center on Philanthropy, Indiana University. "Center on Philanthropy Panel Study: Quick Facts About Charitable Giving." Accessed October 26, 2011. http://www.philanthropy.iupui.edu/Research/Quick\%20facts\%20about\%20cha ritable\%20giving\%20from\%20the.pdf.

Cooper, D., and Kagel, J. "Other-Regarding Preferences: A Selective Survey of Experimental Results." In Handbook of Experimental Economics Volume 2, edited by Kagel, J., and Roth, A., Princeton: Princeton University Press, forthcoming.

Davis, A., Miller, J., and Weber, R. 2011. "Generosity Across Contexts." Pilot study, Experiment 1, Experiment 2. http://dvn.iq.harvard.edu/dvn/dv/alexdavis

DeVoe, S. and S. Iyengar. "Medium of Exchange Matters: What's Fair for Goods is Unfair for Money." Psychological Science 21(2) (2010): 159-162.

Dovidio, J., Piliavin, J., Schroeder, D., and Penner, L. The Social Psychology of Prosocial Behavior. Mahwah, NJ: Lawrence Erlbaum Associates, 2006.

Falk, A. “Gift Exchange in the Field.” Econometrica 75(5) (2007): 1501-11.

Fehr, E., and Schmidt, K. "A Theory of Fairness, Competition, and Cooperation." The Quarterly Journal of Economics 114(3) (1999): 817-68.

Fehr, E., and Schmidt, K. (2006). "The Economics of Fairness, Reciprocity and Altruism: Experimental Evidence and New Theories." In Handbook on the Economics of Giving, Reciprocity and Altruism, Volume 1: Foundations, edited by Kolm, S., and Ythier, J. 615-91, Amsterdam: North Holland Publishing, 2006.

Forsythe, R., Horowitz, J., Savin, N., and Sefton, M. "Fairness in Simple Bargaining Experiments." Games and Economic Behavior 6(3) (1994): 34769.

Frey, B., and Bohnet, I. "Institutions Affect Fairness: Experimental Investigations." Journal of Institutional and Theoretical Economics 151(2) (1995): 286-303.

Frey, B., Savage, D., and Torgler, B. "Behavior Under Extreme Conditions: The Titanic Disaster.” Journal of Economic Perspectives 25(1) (2011): 209-22. 
Hoffman, E., McCabe, K., Shachat, K., and Smith, V. "Preferences, Property Rights, and Anonymity in Bargaining Games." Games and Economic Behavior 7(3) (1994): 346-80.

Karlan, D., and List, J. "Does Price Matter in Charitable Giving? Evidence from a Large-Scale Natural Field Experiment." The American Economic Review, 97(5) (2007): 1774-93.

Krupka, E., and Weber, R. "The Focusing and Informational Effects of Norms on Pro-Social Behavior.” Journal of Economic Psychology 30(3) (2010): 307-20.

Lea, S., and Webley, P. "Money as Tool, Money as Drug: The Biological Psychology of a Strong Incentive." Behavioral and Brain Sciences 29(2) (2006): 161-209.

Levitt, S., and List, J. "What Do Laboratory Experiments Measuring Social Preferences Reveal About the Real World?" The Journal of Economic Perspectives 21(2) (2007): 153-74.

List, J. "On the Interpretation of Giving in Dictator Games." Journal of Political Economy 115(3) (2007): 482-93.

Maris, E. "The social side of noise annoyance." $\mathrm{PhD}$ diss. Universiteit Leiden, 2008.

Mitchell, L., MacDonald, R., and Brodie, E. "Temperature and the Cold Pressor Test." The Journal of Pain 5(4) (2004): 233-237.

NIDCD. “NIDCD Information Clearinghouse.” Accessed October 26, 2011.

http://www.nidcd.nih.gov/health/misc/pages/clearinghouse.aspx

OrganDonor.gov. Accessed October 26, 2011, http://www.organdonor.gov/donation/typesofdonation.htm

OSHA. “Occupational Noise Exposure.” Accessed October 26, 2011.

http://www.osha.gov/pls/oshaweb/owadisp.show_document?p_table=STANDAR DS\&p_id=9735

Royzman, E., and Baron, J. "The Preference for Indirect Harm." Social Justice Research 15(2) (2002): 165-84.

Schaller, M., and Cialdini, R. "The Economics of Empathic Helping: Support for a Mood Management Motive." Journal of Experimental Social Psychology 24(2) (1988): 163-81.

Schreiber, C., and Kahneman, D. "Determinants of the Remembered Utility of Aversive Sounds." Journal of Experimental Psychology: General 129(1) (2000): 27-42. 
Vohs, K., Mead, N., and Goode, M. “The Psychological Consequences of Money. Science 314(5802) (2006): 1154-6. 
Table 1-Mean WTA by Harm Allocation.

\begin{tabular}{lccc}
\hline & $\mathrm{G}_{i}^{H}>0.5$ & $\mathrm{G}_{i}^{H}=0.5$ & $\mathrm{G}_{i}^{H}<0.5$ \\
\cline { 2 - 4 } Mean WTA & 4.22 & 5.25 & 5.74 \\
$\mathrm{SD}$ & 5.99 & 4.23 & 5.59 \\
$\mathrm{~N}$ & 16 & 22 & 15 \\
\hline
\end{tabular}

Notes: $\mathrm{G}_{\mathrm{i}}^{\mathrm{H}}>0.5$ indicates that participants took more than half of the time for themselves, $\mathrm{G}_{\mathrm{i}}{ }^{\mathrm{H}}=0.5$ participants split the time equally, and $\mathrm{G}_{\mathrm{i}}^{\mathrm{H}}<0.5$ participants gave the other person more than half of the time in the ice water.

Table 2. Regressions (OLS) of Generosity on Allocation Context

(1)

(2)

All subjects Inconsistent subjects All subjects

\begin{tabular}{|c|c|c|c|}
\hline Harm context & $\begin{array}{l}0.184^{* * *} \\
(0.043)\end{array}$ & $\begin{array}{l}0.310^{* * *} \\
(0.064)\end{array}$ & $\begin{array}{l}0.223^{* * *} \\
(0.063)\end{array}$ \\
\hline $\begin{array}{l}\text { Order of choices } \\
\text { (harm then money) }\end{array}$ & & & $\begin{array}{l}-0.062 \\
(0.053)\end{array}$ \\
\hline $\begin{array}{l}\text { Harm context } \\
\text { X Order of choices }\end{array}$ & & & $\begin{array}{c}0.068 \\
(0.086)\end{array}$ \\
\hline Female & & & $\begin{array}{c}0.025 \\
(0.053)\end{array}$ \\
\hline Age & & & $\begin{array}{c}0.005 \\
(0.003)\end{array}$ \\
\hline WTA & & & $\begin{array}{c}0.002 \\
(0.004)\end{array}$ \\
\hline Harm context X WTA & & & $\begin{array}{c}-0.013^{* * *} \\
(0.004)\end{array}$ \\
\hline Constant & $\begin{array}{l}0.299^{* * *} \\
(0.030)\end{array}$ & $\begin{array}{l}0.299^{* * *} \\
(0.045)\end{array}$ & $\begin{array}{l}0.174^{*} \\
(0.097)\end{array}$ \\
\hline $\mathrm{R}^{2}$ & 0.624 & 0.544 & 0.193 \\
\hline Observations (subjects) & $\begin{array}{l}108 \\
(54) \\
\end{array}$ & $\begin{array}{c}64 \\
(32)\end{array}$ & $\begin{array}{l}108 \\
(54)\end{array}$ \\
\hline
\end{tabular}

Models 1 and 2 include subject-specific fixed effects. Model 3 includes robust standard errors, clustered by subject ${ }^{*}-p<0.1,{ }^{* *}-p<0.05,{ }^{* * *} p<0.01$ 
Table 3. Summary statistics for generosity by context (Experiment 2)

\begin{tabular}{ccccc}
\hline & $G_{i}^{M+}$ & $G_{i}^{M-}$ & $G_{i}^{N M+}$ & $G_{i}^{N M-}$ \\
\hline Mean & 0.31 & 0.26 & 0.54 & 0.38 \\
Median & 0.40 & 0.30 & 0.50 & 0.50 \\
$G_{i}=0$ & $18 \%$ & $32 \%$ & $2 \%$ & $14 \%$ \\
$G_{i}=0.5$ & $36 \%$ & $32 \%$ & $61 \%$ & $48 \%$ \\
$G_{i}>0.5$ & $2 \%$ & $2 \%$ & $25 \%$ & $7 \%$ \\
\hline
\end{tabular}


Table 4. Regressions (OLS) of Generosity on Allocation Context

\begin{tabular}{|c|c|c|c|c|c|}
\hline & (1) & (2) & (3) & (4) & (5) \\
\hline & \multirow{2}{*}{$\begin{array}{c}\text { All } \\
\text { subjects }\end{array}$} & \multirow{2}{*}{$\begin{array}{l}\text { Inconsistent } \\
\text { subjects }\end{array}$} & \multicolumn{2}{|c|}{ Subjects with } & All \\
\hline & & & $\mathrm{WTP}_{\text {goods }}>0$ & $\mathrm{WTP}_{\text {goods }} \geq 0.5$ & subjects \\
\hline Non-monetary & $\begin{array}{l}0.228^{* * *} \\
(0.040)\end{array}$ & $\begin{array}{l}0.296^{* * *} \\
(0.048)\end{array}$ & $\begin{array}{c}0.164^{* * *} \\
(0.042)\end{array}$ & $\begin{array}{l}0.167^{* *} \\
(0.065)\end{array}$ & $\begin{array}{l}0.290^{\text {*** }} \\
(0.057)\end{array}$ \\
\hline Negative & $\begin{array}{l}-0.044 \\
(0.039)\end{array}$ & $\begin{array}{l}-0.056 \\
(0.047)\end{array}$ & $\begin{array}{l}-0.048 \\
(0.041)\end{array}$ & $\begin{array}{l}-0.039 \\
(0.065)\end{array}$ & $\begin{array}{l}-0.044^{* *} \\
(0.021)\end{array}$ \\
\hline $\begin{array}{l}\text { Non-monetary X } \\
\text { Negative }\end{array}$ & $\begin{array}{l}-0.110^{*} \\
(0.056)\end{array}$ & $\begin{array}{l}-0.143^{* *} \\
(0.068)\end{array}$ & $\begin{array}{l}-0.054 \\
(0.059)\end{array}$ & $\begin{array}{l}-0.043 \\
(0.091)\end{array}$ & $\begin{array}{l}-0.197^{* *} \\
(0.074)\end{array}$ \\
\hline $\begin{array}{l}\text { Order (position of } \\
\text { allocation choice) }\end{array}$ & $\begin{array}{l}-0.002 \\
(0.013)\end{array}$ & $\begin{array}{l}-0.001 \\
(0.016)\end{array}$ & $\begin{array}{l}-0.018 \\
(0.014)\end{array}$ & $\begin{array}{l}-0.012 \\
(0.021)\end{array}$ & $\begin{array}{l}-0.001 \\
(0.016)\end{array}$ \\
\hline Female & & & & & $\begin{array}{l}-0.020 \\
(0.043)\end{array}$ \\
\hline Age & & & & & $\begin{array}{l}0.003^{* *} \\
(0.001)\end{array}$ \\
\hline $\mathrm{WTP}_{\text {goods }}$ & & & & & $\begin{array}{l}0.099^{* *} \\
(0.037)\end{array}$ \\
\hline $\begin{array}{l}\text { WTP }_{\text {goods }} \text { X Non- } \\
\text { monetary-Positive }\end{array}$ & & & & & $\begin{array}{c}-0.134^{* * *} \\
(0.050)\end{array}$ \\
\hline $\mathrm{WTA}_{\text {noise }}$ & & & & & $\begin{array}{c}0.002 \\
(0.003)\end{array}$ \\
\hline $\begin{array}{l}\text { WTA }_{\text {noise }} \text { X Non- } \\
\text { monetary-Negative }\end{array}$ & & & & & $\begin{array}{c}0.005 \\
(0.006)\end{array}$ \\
\hline Constant & $\begin{array}{l}0.311^{* * *} \\
(0.045)\end{array}$ & $\begin{array}{l}0.267^{* * *} \\
(0.054)\end{array}$ & $\begin{array}{l}0.366^{* * *} \\
(0.046)\end{array}$ & $\begin{array}{l}0.373^{* * *} \\
(0.069)\end{array}$ & $\begin{array}{l}0.187^{* *} \\
(0.074)\end{array}$ \\
\hline $\mathrm{R}^{2}$ & 0.565 & 0.569 & 0.569 & 0.451 & 0.252 \\
\hline $\begin{array}{l}\text { Observations } \\
\text { (subjects) }\end{array}$ & $\begin{array}{l}176 \\
(44) \\
\end{array}$ & $\begin{array}{l}136 \\
(34) \\
\end{array}$ & $\begin{array}{l}136 \\
(34) \\
\end{array}$ & $\begin{array}{r}72 \\
(18) \\
\end{array}$ & $\begin{array}{l}176 \\
(44) \\
\end{array}$ \\
\hline
\end{tabular}

Notes: Models 1 through 4 include subject-specific fixed effects. Model 5 includes robust standard errors, clustered by subject; ${ }^{*}-\mathrm{p}<0.1,{ }^{* *}-\mathrm{p}<0.05,{ }^{* * *} \mathrm{p}<0.01$ 
Table 5. Correlation matrix between the four allocation decisions.

\begin{tabular}{ccccc}
\hline & $G_{i}^{M+}$ & $G_{i}^{M-}$ & $G_{i}^{N M+}$ & $G_{i}^{N M-}$ \\
\hline$G_{i}^{M+}$ & 1 & & & \\
$G_{i}^{M-}$ & $0.83^{* * *}$ & 1 & & \\
$G_{i}^{N M+}$ & 0.11 & 0.20 & 1 & \\
$G_{i}^{N M-}$ & 0.18 & 0.19 & 0.12 & 1 \\
\hline
\end{tabular}

Table 6. Principal components analysis of the four allocation decisions.

\begin{tabular}{lll}
\hline & Component 1 & Component 2 \\
\hline $\mathrm{G}^{\mathrm{M}+}$ & 0.650 & -0.302 \\
$\mathrm{G}^{\mathrm{M}-}$ & 0.664 & -0.210 \\
$\mathrm{G}^{\mathrm{NM}+}$ & 0.243 & 0.743 \\
$\mathrm{G}^{\mathrm{NM}-}$ & 0.278 & 0.560 \\
\hline Eigenvalue & 1.97 & 0.97 \\
Proportion of Variance & 0.49 & 0.25 \\
Cumulative Proportion & 0.49 & 0.74 \\
\hline
\end{tabular}




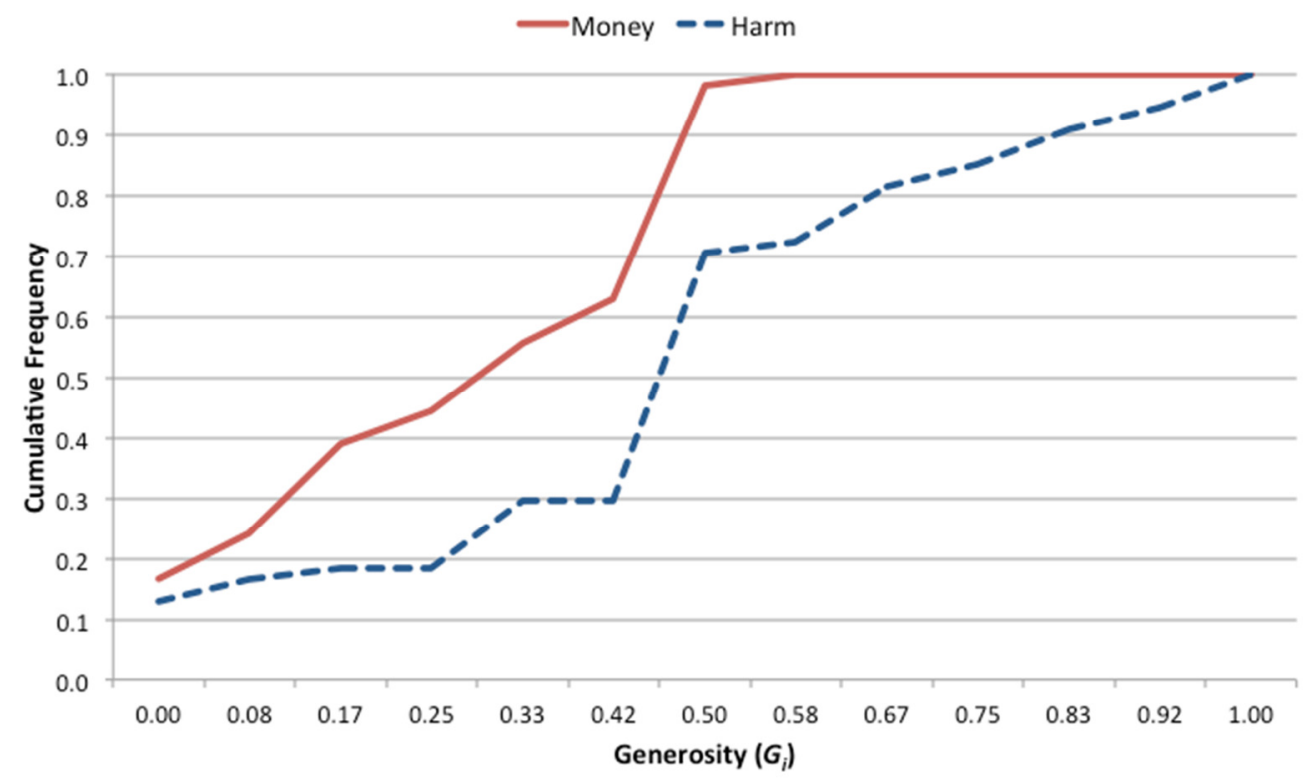

Figure 1. Cumulative distribution of generosity by context (Experiment 1)

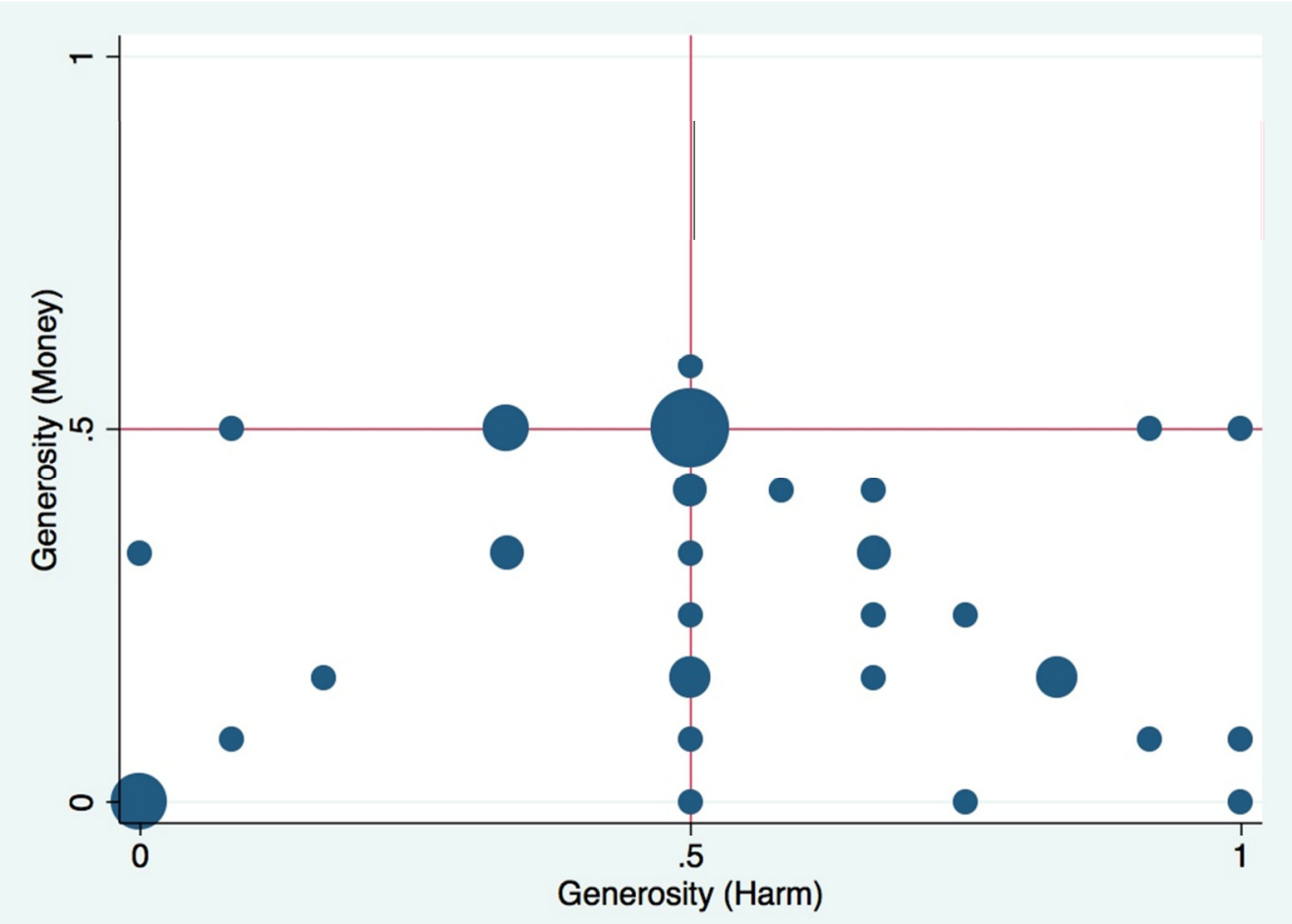

Figure 2. Joint distribution of generosity in harm and money by subject (Experiment 1) 


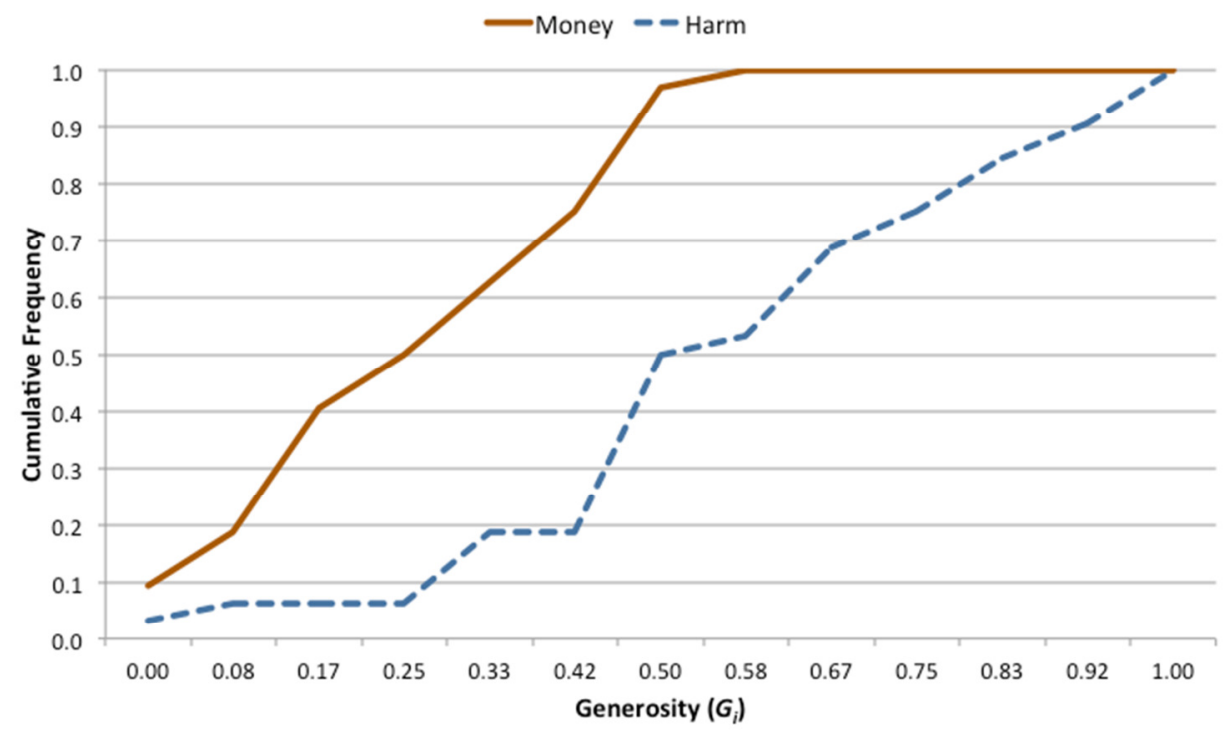

Figure 3. Cumulative distribution of generosity by context (Experiment 1, Inconsistent subjects only)

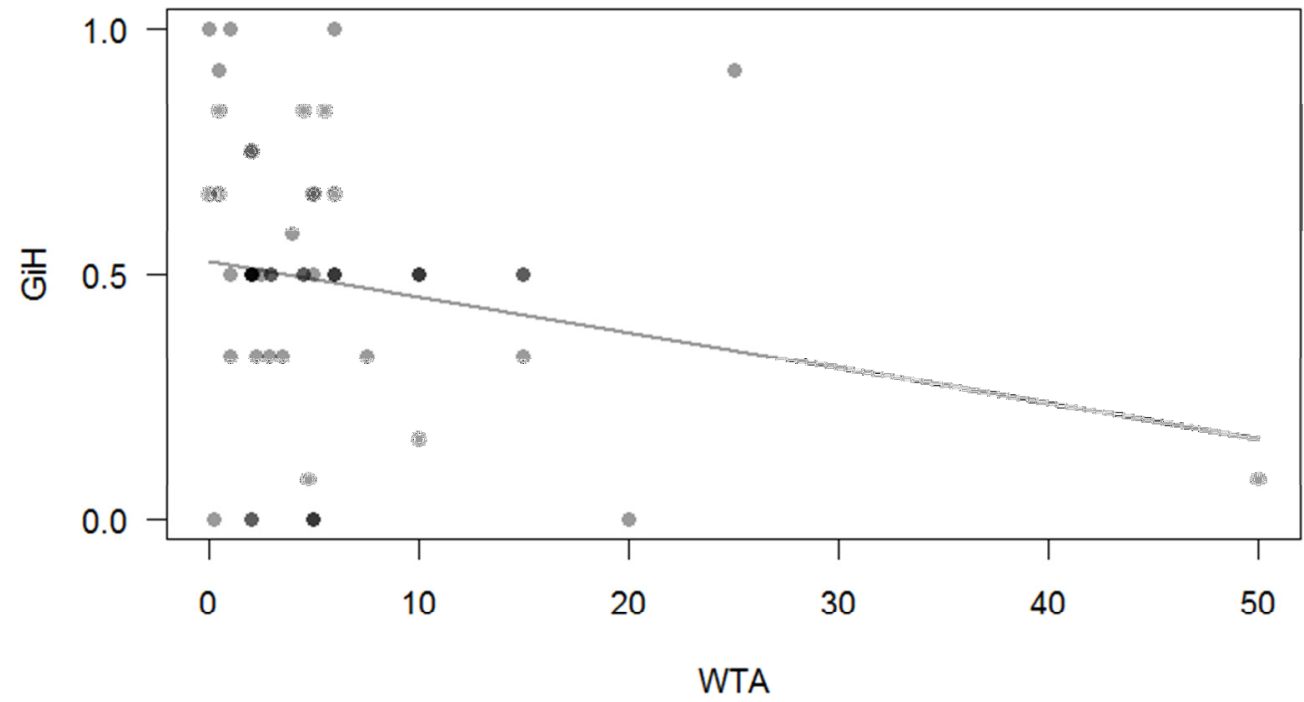

Figure 4. Scatter plot and linear correlation between dictators' Willingness to Accept money to put their hand in ice water for sixty seconds (x-axis) and the percent of time kept in the allocation of the ice-water experience (y-axis) $\left(G_{i}{ }^{H}\right)$. 


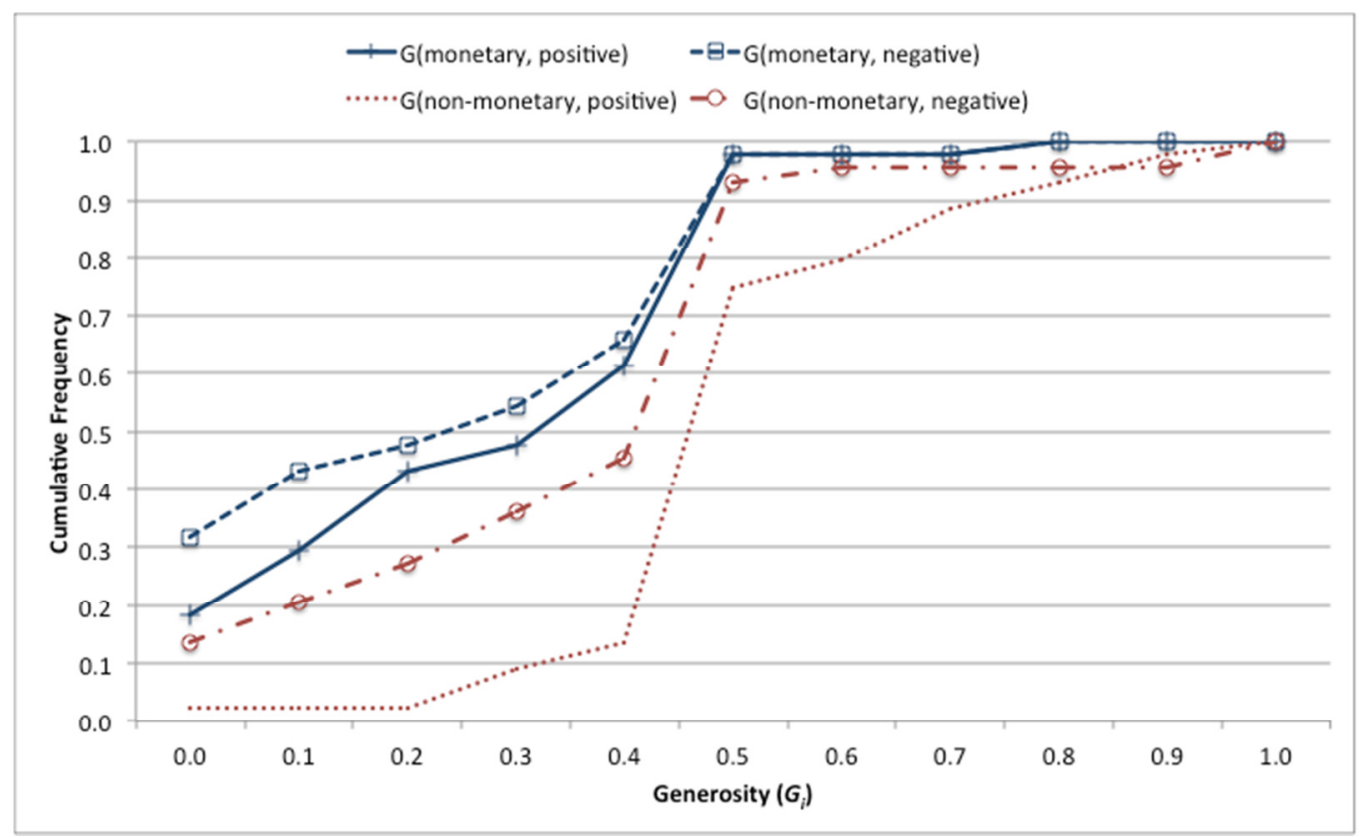

Figure 5. Cumulative distribution of generosity by context (Experiment 2)

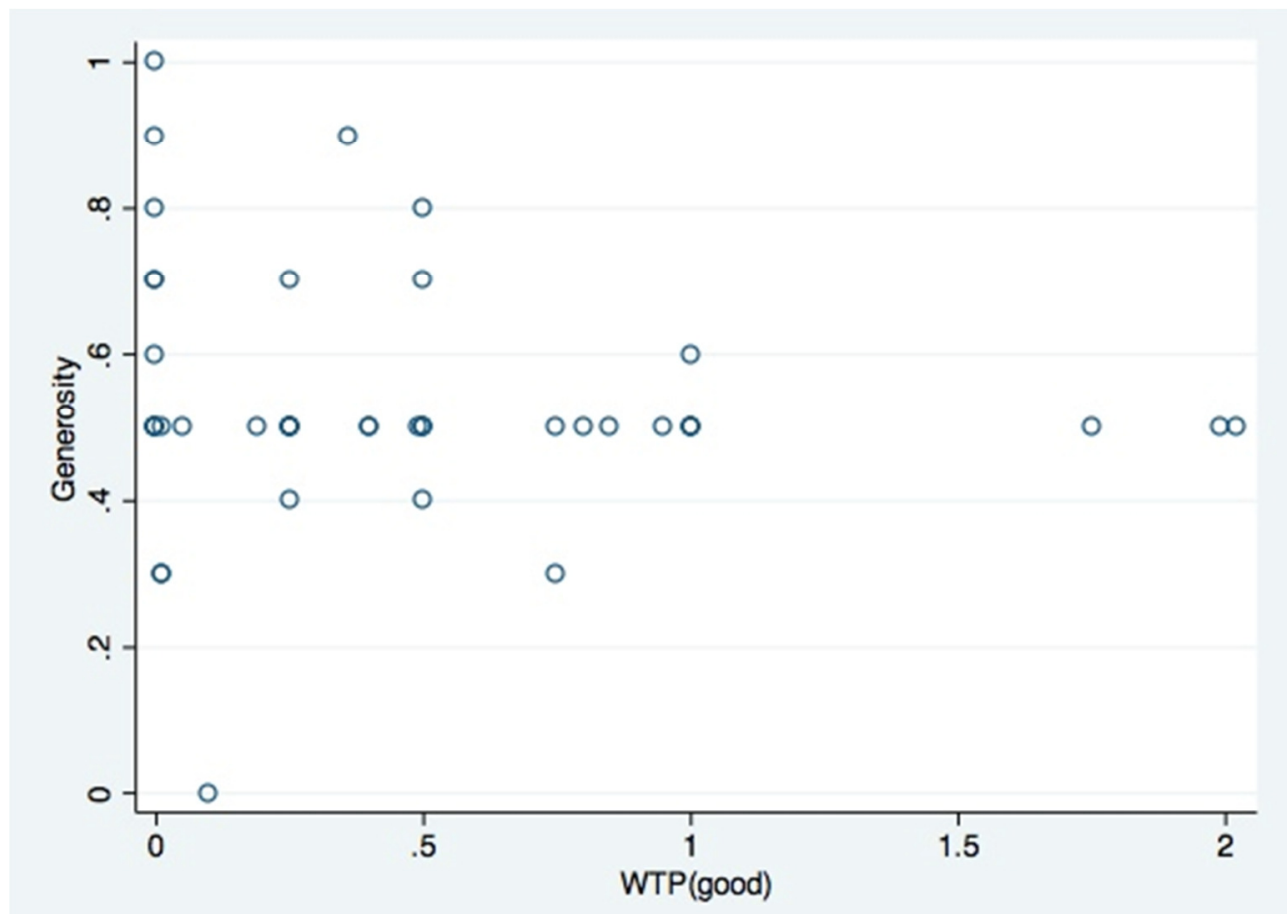

Figure 6. Scatterplot of generosity in Non-monetary-Good context with WTP for goods used in that context (Experiment 2) 


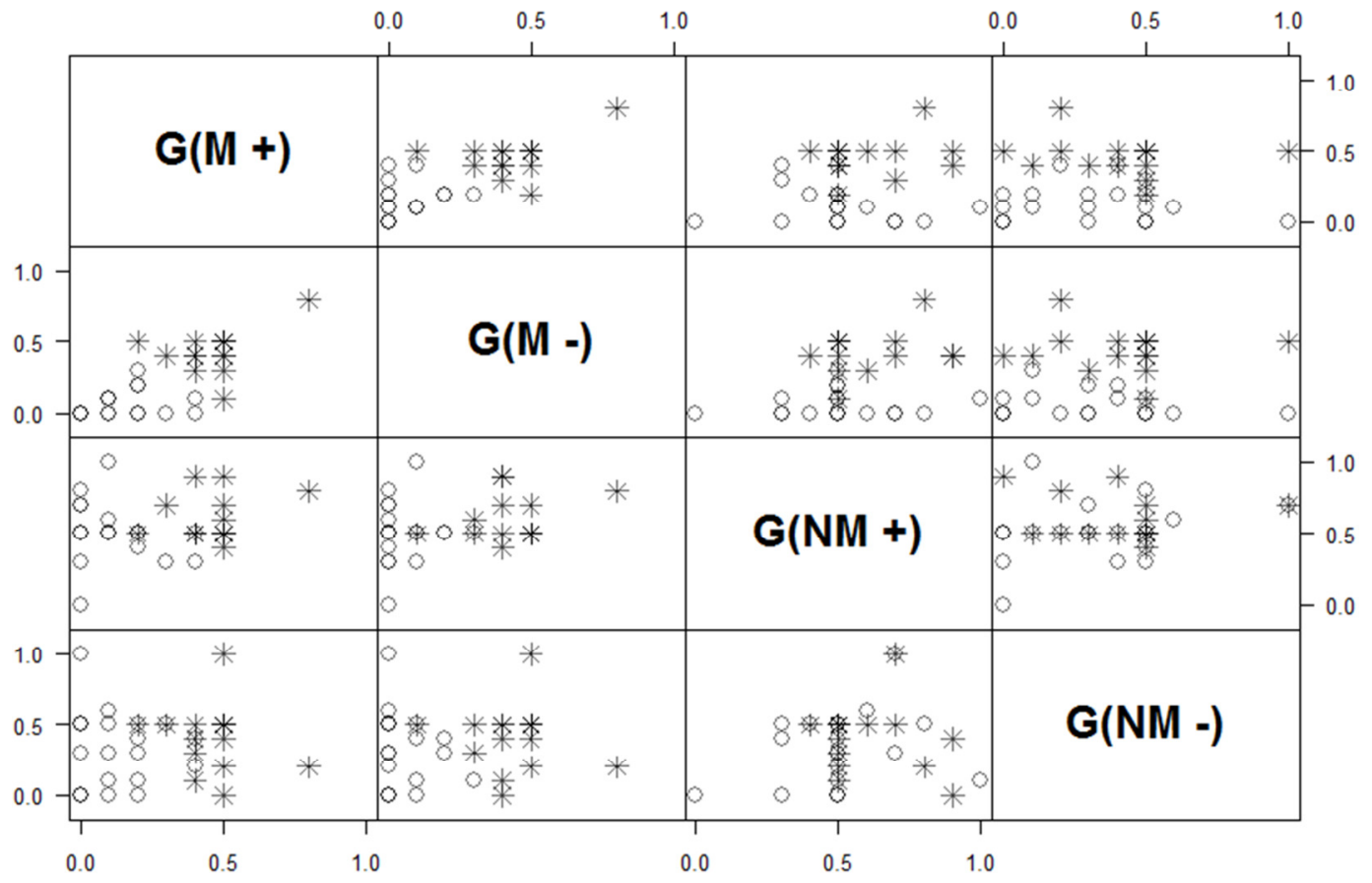

Figure 7. Pairwise distributions of Gi. a)

For the lower triangle, the $x$-axis for the graph is the variable above the graph and the $y$-axis is the variable to the right of the graph. For the upper triangle, the x-axis for the graph is the variable below the graph and the y-axis is the variable to the left of the graph. 


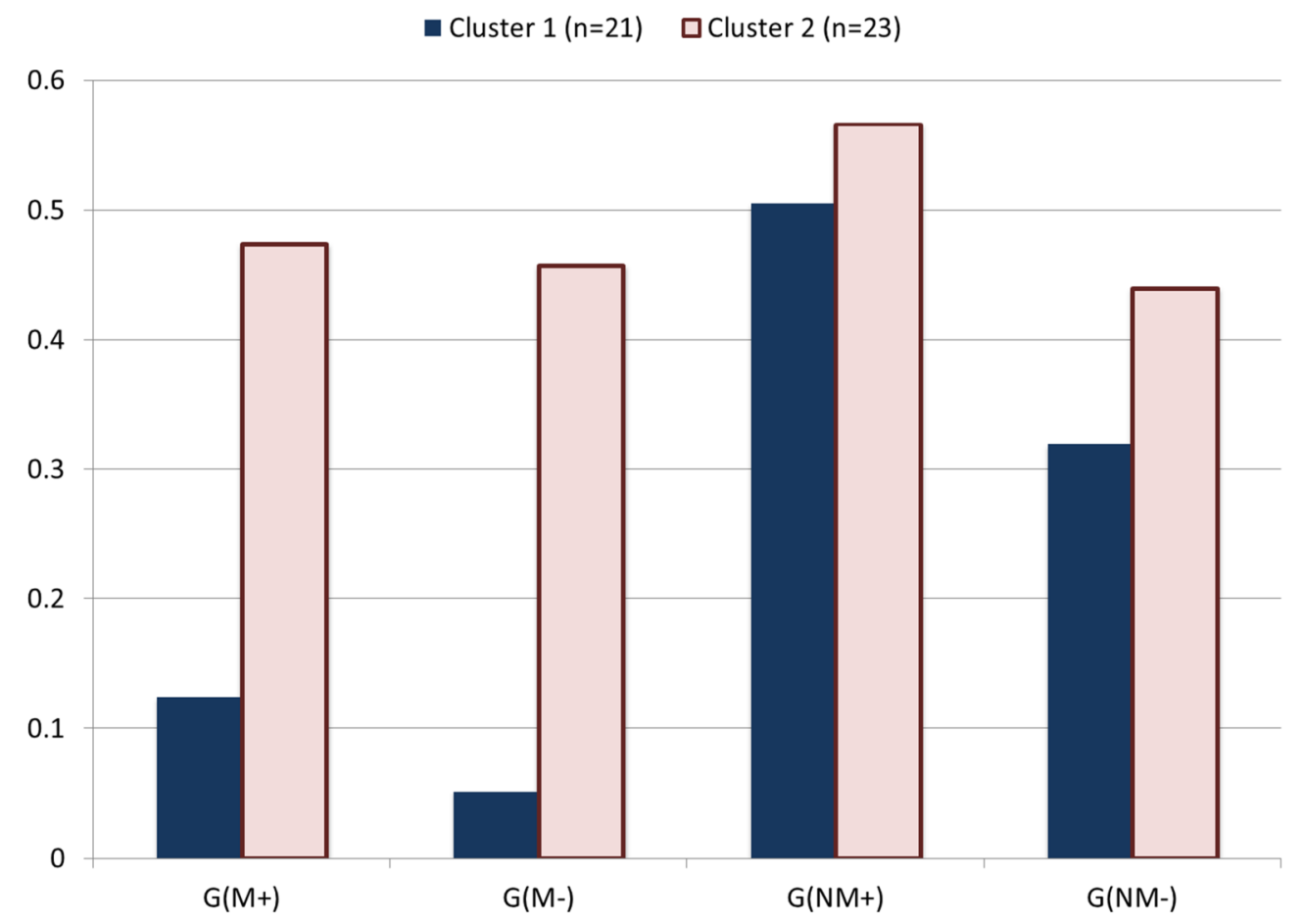

Figure 8. Mean generosity exhibited by participants in each cluster, by context. The two equidistant participants are omitted. 